\title{
Estimasi Jumlah Murid Baru Menggunakan Metode Forecasting
}

\author{
Dwi Harini ${ }^{1 *}$, Lilia Sinta Wahyuniar ${ }^{2}$ \\ ${ }^{1}$ Sistem Informasi, Universitas Nusantara PGRI Kediri, Indonesia \\ ${ }^{2}$ Teknik Informatika, Universitas Nusantara PGRI Kediri, Indonesia \\ *dwiharini@unpkediri.ac.id
}

\begin{tabular}{|c|c|}
\hline Article Info & Abstract \\
\hline $\begin{array}{l}\text { Received } \\
29 \text { September } 2021\end{array}$ & $\begin{array}{l}\text { Of the many forecasting methods or forecasting, the Linear Regression } \\
\text { Method can be used to predict or predict the number of new students or } \\
\text { students in the new academic year at the Islamic Junior High School } \\
\text { "Al-H***h in Malang Regency. This study uses the MAD, MSE, and }\end{array}$ \\
\hline $\begin{array}{l}\text { Revised } \\
28 \text { October } 2021\end{array}$ & $\begin{array}{l}\text { MAPE approaches. The data used is historical data on the number of } \\
\text { students obtained for } 9 \text { years starting from the 2013-2014 school year } \\
\text { until the 2021-2022 school year. By estimating or forecasting, helping }\end{array}$ \\
\hline $\begin{array}{l}\text { Accepted } \\
06 \text { November } 2021\end{array}$ & $\begin{array}{l}\text { the school, especially the AL- } H^{* * * * h} \text { Islamic Junior High School, } \\
\text { know the number of new students accepted at the school in the 2022- } \\
2023 \text { school year. }\end{array}$ \\
\hline
\end{tabular}

Keywords

Forecasting

Regresi Linear

Standar Error

Copyright@2020 JIM, all rights reserved. Authors agree that this article remains permanently open access under the terms of the Creative Commons Attribution-ShareAlike 4.0 International License

How to Cite:

Harini, D., \& Wahyuniar, L. S. (2021). Estimasi Jumlah Murid Baru Menggunakan Metode Forecasting. Journal of Instructional Mathematics, 2(2), 64-70.

\section{PENDAHULUAN}

Meramalkan atau melakukan estimasi sesuatu, misalnya meramalkan penjualan suatu produk, meramalkan pembelian stok barang, meramalkan persediaan suatu barang, meramalkan jumlah murid baru di tahun ajaran berikutnya pada suatu sekolah adalah hal yang sangat penting. Bahkan peramalan adalah suatu tindakan yang penting dalam suatu perencanaan pada bidang apapun, agar tujuan yang ingin dicapai atau yang telah ditetapkan dapat terwujud secara optimal.

Setiap tahun, menjelang tahun pelajaran baru, setiap sekolah baik dari tingkat Play Grup, Taman Kanak-Kanak, Sekolah Dasar, Sekolah Menengah Pertama dan yang sederajat ,Sekolah Menengah Atas dan yang sederajat, baik yang berstatus sebagai sekolah negeri maupun sekolah swasta melakukan pendaftaran murid atau siswa siswi atau santri baru. Jika pada sekolah-sekolah yang berstatus sekolah negeri sudah ada rombel atau rombongan belajar, yang sudah mempunyai kuota atau kursi yang disediakan dan kuota tersebut hampir keseluruhan kursi terpenuhi. Berbeda dengan sekolah-sekolah yang berstatus swasta, pada penerimaan murid baru pada tahun ajaran baru, banyak kursi-kursi kosong yang belum terisi.

Dengan pesatnya perkembangan teknologi informasi saat ini, maka persaingan sekolah-sekolah swasta lebih besar dan berat sehingga sekolah-sekolah swasta tersebut berlomba untuk melakukan promosi agar dapat menjaring murid baru yang sesuai dengan kuota yang disediakan. Masalah ini juga terjadi pada Sekolah 
Menengah Pertama Islam "Al-H****h di Kabupaten Malang, sehingga perlu dilakukan peramalan atau estimasi jumlah murid ditahun berikutnya agar terjadi kondisi yang kondusif, dan kesesuaian jumlah murid, jumlah karyawan, sarana prasarana yang tersedia sehingga proses belajar mengajar berjalan efektif dan efisien. Peramalan merupakan alat bantu yang penting dalam perencanaan yang efektif dan efisien (Makridakis, Wheelwright \& McGee, 1999).

Dengan jumlah murid yang fluktuatif dari tahun ke tahun selama 9 tahun, maka perlu dilakukan estimasi jumlah murid baru pada tahun pelajaran baru berikutnya pada Sekolah Menengah Pertama Islam "Al-H****h menggunakan Metode Regresi Linier, karena metode ini simple, mudah dipahami dan dapat digunakan untuk memprediksi atau meramalkan nilai di masa depan. Tentu saja hasil peramalan merupakan nilai estimasi sehingga adanya kemungkinan nilai dari hasil peramalan tersebut tidak sesuai dengan data aktual.

Hasil dari Metode Regresi Linier diuji tingkat errornya dengan pendekatan Metode MAD, MADE, MSE. Penelitian terdahulu (Sanny et al., 2013) menggunakan metode MAD (Mean Absolute Deviation) dan MSE (Mean Squared Error), metode MSE juga digunakan (Prakoso, Kusnadi \& Nugraha, 2021) sebagai ukuran standart error pada peramalan penjualan produk, sedangkan (Khusna, 2018) menggunakan metode MAPE (Mean Absulute Percentage Error) sebagai ukuran standart error untuk meramalkan jumlah murid baru. Hasil peramalan atau estimasi dengan akurasi tinggi adalah yang memiliki nilai evaluasi error paling rendah.

\section{Peramalan (Forcasting)}

\section{METODE PENELITIAN}

Peramalan memang tidak akan tepat atau akurat seratus persen, karena di masa mendatang tidak ada yang tahu kepastian atau ketidakpastian akan terjadi. Akan tetapi dengan teknik ilmiah, yaitu menggunakan metode peramalan, dapat meminimalkan kesalahan dan memberikan kemungkinan terbaik atas suatu kejadian atau keadaan di masa mendatang.

Forcasting dilakukan dengan membuat prediksi atau peramalan tentang apa yang akan terjadi di masa depan dengan melihat keadaan di masa sebelumnya (Khotimah \& Nindyasari, 2017). Menurut Yanti, Tuningrat \& Wiranatha (2016), dengan menggunakan peramalan atau Forcasting perusahaan dapat memperkirakan apa yang akan terjadi di masa datang dengan menggunakan datadata di masa lampau atau data historis suatu perusahaan. Sedangkan Wardah \& Iskandar (2017) mengatakan bahwa peramalan merupakan sebuah metode untuk memperhitungkan nilai di masa yang akan datang dengan menggunakan data di masa lalu.

Selain data-data jumlah murid baru yang diperoleh pada tahun-tahun sebelumnya, tentunya ada faktor-faktor lain yang mempengaruhi penerimaan atau jumlah murid baru pada Sekolah Menengah Pertama Islam "Al-H****h ini yaitu gencarnya promosi yang dilakukan pihak yayasan baik secara offline dengan memasang baner di jalan-jalan dan juga secara online melalui social media tentang profil sekolah tersebut dan prestasi-prestasi yang didapat sekolah tersebut baik prestasi akademik maupun prestasi non akademik pada berbagai kejuaraan di tingkat lokal maupun tingkat nasional juga mempengaruhi banyaknya murid baru 
yang diperoleh ditahun-tahun berikutnya. Masyarakat juga mempertimbangkan sarana prasarana yang dimiliki Sekolah Menengah Pertama Islam "Al-H****h untuk berminat mendaftar di sekolah tersebut diantara sarana laboratoriun IPA, UKS, Perpustakaan dan sebagainya.

\section{Regresi Linier}

Regresi linier sederhana adalah regresi linier yang didasarkan pada hubungan fungsional ataupun kausal satu variable inependen dengan satu variable dependen (Sugiyono, 2011). Regresi linier sederhana adalah salah satu regresi linier yang digunakan untuk mengestimasi hubungan anata dua dua variable dalam penelitian kuantitatif. Menurut Sugiyono (2011), variabel bebas atau independent variable merupakan variable yang mempengaruhi atau yang menjadi sebab perubahannya atau timbulnya variable terikat (X), sedangkan variable terikat (dependent variable) merupakan variable yangdipengaruhi atau yang menjadi akibat karena adanya variable bebas (Y).

Regresi dipakai dalam menentukan sifat-sifat serta kekuatan relasi antara dua variable juga meramalkan nilai sebuah variable yang belum diketahuai yang berlandaskan pengamatan di masa lampau pada variable itu juga variable-variabel lain (Levin \& David, 1998). Rumus yang digunakan sebagai berikut.

$$
\begin{gathered}
Y=a+b X \\
a=\frac{\sum Y-b \sum X}{n} \\
b=\frac{n\left(\sum X Y\right)-\left(\sum X\right)\left(\sum Y\right)}{n \sum X^{2}-\left(\sum X\right)^{2}}
\end{gathered}
$$

Dimana: $Y=$ variable terikat atau variable yang diramalkan, $X=$ variable bebas atau variable waktu, $a=$ konstanta (intersep), $b=$ konstatnta regresi (slope), $n=$ banyaknya data.

\section{MAD, MSE dan MAPE}

Setiap melakukan estimasi atau peramalan tidaklah mungkin mendapatkan hasil yang benar-benar tepat atau akurat. Untuk mengetahui metode yang kita pakai mendekati akurat yaitu dengan mengukur kesalahan atau perhitungan error. Ukuran akurasi hasil peramalan yang merupakan ukuran kesalahan peramalan merupakan ukuran tentang tingkat perbedaan antara hasil peramalan dengan permintaan yang terjadi (Nasution, 2008). Rumus yang digunakan untuk menetapkan standart perbedaan (standart error) diantaranya adalah MAD, MSE dan MAPE.

\section{MAD (Mean Absolute Deviation)}

MAD adalah rat-rata kesalahan mutlak selama periode tertentu tanpa memperhatikan apakah hasil peramalan lebih besar atau lebih kecil disbanding kenyataannya, dengan kata lain MAD adalah rat-rata dari nilai absolut simpangan, (Gaspersz, 2008). 


$$
M A D=\sum\left|\frac{A_{t}-F_{t}}{n}\right|
$$

Dimana: $A_{t}=$ data aktual, $F_{t}=$ hasil peramalan, $n=$ total periode yang dimiliki actual data dan peramalan.

MSE (Mean Square Error)

MSE dihitung dengan menjumlahkan kuadrat semua kesalahan peramalan pada setiap periode dan membaginya dengan jumlah periode peramalan (Gaspersz, 2008).

$$
M S E=\sum \frac{\left(A_{t}-F_{t}\right)^{2}}{n}
$$

Dimana: $A_{t}=$ data aktual, $F_{t}=$ hasil peramalan, $n=$ total periode yang dimiliki actual data dan peramalan.

MAPE (Mean Absulute Percentage Error)

MAPE adalah ukuran kesalahan relative, biasanya lebih berarti dibandingkan dengan MAD karena MAPE menyatakan persentase kesalahan hasil peramalan terhadap permintaan actual selama periode tertentu yang akan memberikan informasi persentase kesalahan terlalu tinggi atau terlalu rendah, dengan kata lain MAPE merupakan rat-rata kesalahan mutlak selama periode tertentu yang kemudian dikalikan $100 \%$ agar mendapatkan hasil secara prosentase.

$$
M A P E=\left(\frac{100}{n}\right) \sum\left|A_{t}-\frac{F_{t}}{A_{t}}\right|
$$

Dimana: $A_{t}=$ data aktual, $F_{t}=$ hasil peramalan, $n=$ total periode yang dimiliki actual data dan peramalan. Sedangkan untuk interpretasi nilai MAPE, tentang kategori akuraasi peramalan, yaitu merujuk pada Khusna (2018) seperti pada

\begin{tabular}{|c|c|}
\hline Nilai MAPE & Akurasi Peramalan \\
\hline MAPE $\leq 10 \%$ & Tinggi \\
\hline $10 \%<$ MAPE $\leq 20 \%$ & Baik \\
\hline $20 \%<$ MAPE $\leq 50 \%$ & Cukup \\
\hline MAPE $>50 \%$ & Rendah \\
\hline
\end{tabular}
Tabel 1 .

Tabel 1. Akurasi MAPE

Hasil peramalan adalah akurasi atau ketepatan. Akurasi suatu peramalan dapat dilihat dari nilai MAD, MSE dan MAPE terkecil. 


\section{HASIL DAN PEMBAHASAN}

Untuk melakukan estimasi atau peramalan jumlah murid baru di tahun 2023, digunakan data yang ada selama 9 tahun.

Tabel 2. Jumlah Murid Baru Dari Tahun 2013-2021

\begin{tabular}{cccc}
\hline Tahun & Laki-laki & Perempuan & Jumlah \\
\hline $2013-2014$ & 65 & 73 & 138 \\
$2014-2015$ & 71 & 69 & 140 \\
$2015-2016$ & 83 & 71 & 154 \\
$2016-2017$ & 88 & 76 & 164 \\
$2017-2018$ & 77 & 58 & 135 \\
$2018-2019$ & 70 & 82 & 152 \\
$2019-2020$ & 77 & 75 & 152 \\
$2020-2021$ & 73 & 72 & 145 \\
$2021-2022$ & 80 & 74 & 154 \\
\hline
\end{tabular}

Dari data di atas, dilakukan perhitungan dengan menggunakan Metode Regresi Linier.

Tabel 3. Perhitungan Regresi Linier

\begin{tabular}{ccccccc}
\hline Tahun & $X_{i}$ & $Y_{i}$ & $X_{i} . Y_{i}$ & $X_{i}^{2}$ & $Y_{i}^{\prime}$ & $\left|Y_{i}-Y_{i}^{\prime}\right|$ \\
\hline $2013-2014$ & 1 & 138 & 138 & 1 & 97,79 & 40,21 \\
$2014-2015$ & 2 & 140 & 280 & 4 & 107,51 & 32,49 \\
$2015-2016$ & 3 & 154 & 462 & 9 & 117,23 & 36,77 \\
$2016-2017$ & 4 & 164 & 656 & 16 & 126,95 & 37,05 \\
$2017-2018$ & 5 & 135 & 675 & 25 & 136,67 & 1,67 \\
$2018-2019$ & 6 & 152 & 912 & 36 & 146,39 & 5,6 \\
$2019-2020$ & 7 & 152 & 1064 & 49 & 156,11 & 4,11 \\
$2020-2021$ & 8 & 145 & 1160 & 64 & 165,83 & 20,83 \\
$2021-2022$ & 9 & 154 & 1386 & 81 & 175,55 & 21,55 \\
\hline Jumlah & 45 & 1230 & 6733 & 285 & & 200,28 \\
\hline
\end{tabular}

Menggunakan rumus (2) dan (3) diperoleh $b=9,72$ dan $a=88,07$ sehingga persamaan regresinya $\hat{Y}=88,07+9,72 X$ dan $Y_{10}=88,07+9,72(10)=185,27 \approx 185 . Y_{10}$ menunjukkan jumlah murid baru tahun pelajaran 2022-2023. Jumlah siswa atau murid baru pada tahun pelajaran 2021-2022 menurut data yang diperoleh dari Sekolah Menengah Pertama Islam “Al-H****h sebanyak 154 orang. Sehingga estimasi jumlah murid baru yang diperolehan pada tahun pelajaran 2022-2023 mengalami peningkatan dibandingkan dengan tahun sebelumnya.

Akurasi nilai MAD dan nilai MSE yang terkecil yang digunakan sehingga suatu metode peramalan dapat digunakan, maka dari hasil perhitungan menurut rumus (4) $\mathrm{MAD}=\frac{200,28}{9}=22,25$, sesuai rumus (5) $\mathrm{MSE}=\frac{78,29}{9}=8,7$. Nilai MSE yang diperoleh kurang dari nilai MAP. Menurut rumus (6) MAPE $=\frac{136,1}{9}$ $=15,12 \%$. Sesuai Tabel 1 bahwa nilai MAPE, $10 \%<$ MAPE $\leq 20 \%$, sehingga nilai akurasi peramalan dikategorikan baik. Dalam penelitian ini nilai MAPE yang 
digunakan sebagai acuan untuk menentukan metode regresi linier sebagai metode yang dapat digunakan melakukan estimasi jumlah murid baru tahun pelajaran 2022-2023 pada SMP Islam "Al-H****h.

Dapat diestimasi bahwa jumlah murid baru yang diperoleh SMP Islam "Al$\mathrm{H}^{* * * * \mathrm{~h}}$ pada tahun pelajaran 2022-2023 sebanyak 185 siswa. Sedangkan standart error-nya menurut perhitungan yang telah dilakukan sesuai rumus (4), (5), dan (6) $\mathrm{MAD}=22,25$. $\mathrm{MSE}=8,7$ dan $\mathrm{MAPE}=15,12 \%$. Sesuai Tabel 1, akurasi nilai MAPE dikatakan bahwa estimasi menggunakan metode peramalan regresi linier dengan nilai standart error MAPE $=15,12 \%$ tersebut dikatagorikan baik.

\section{KESIMPULAN}

Dari penilitian yang telah dilakukan, didapat hasil jumlah murid atau siswa siswi baru pada tahun ajaran 2022-2023 di Sekolah Menengah Pertama Islam Al$\mathrm{H}^{* * * * h}$ Kabupaten Malang sejumlah 185 murid sedang metode regresi linier sebagai alat utuk mengestimasi jumlah murid baru tersebut dikategorikan baik dengan nilai MSE sebesar 8,7 dan MAPE sebesar 15,12\% sehingga metode regresi linier yang digunakan umtuk melakukan penerimaan jumlah murid baru di tahun-tahun pelajaran berikutnya juga dapat diimplementasikan. Metode peramalan regresi linier sangat membantu pihak sekolah khususnya SMP Islam Al-H****h mengetahui jumlah murid baru yang diperoleh di tahun-tahun berikutnya.

\section{REFERENSI}

Gaspersz, V. (2008). Production Planning and Inventory Control. Jakarta: PT Gramedia Pustaka Utama.

Khotimah, T., \& Nindyasari, R. (2017). Forecasting Dengan Metode Regresi Linier Pada Sistem Penunjang Keputusan Untuk Memprediksi Jumlah Penjualan Batik (Studi Kasus Kub Sarwo Endah Batik Tulis Lasem). Jurnal Mantik Penusa, 1(1), 71-75.

Khusna, S. A. (2018). Analisis Jumlah Siswa Baru Dengan Metode Peramalan Eksponensial Smoothing Di MTs Abdulloh Mojo [HTML File]. URL: http://simki.unpkediri.ac.id/detail/14.1.01.05.0064.

Levin, R. I., \& David S. R. (1998). Statistics for Manajement. Prentice-Hall.

Makridakis, S., Wheelwright, S. C., \& McGee, V. E. (1999). Metode dan aplikasi peramalan. Jakarta: Erlangga.

Nasution, A. H. (2008). Perencanaan dan Pengendalian Produksi. Surabaya: Prima Printing.

Prakoso, I. A., Kusnadi, K., \& Nugraha, B. (2021). Peramalan Penjualan Produk Dengan Metode Regresi Linear Dan Aplikasi POM-QM di PT XYZ. Widya Teknik, 20(1), 17-20. https://doi.org/10.33508/wt.v20i1.3158

Sanny, L., Sarjono, H., Trend, W., \& Moving, W. (2013). Peramalan Jumlah Siswa/I Sekolah Menengah Atas Swasta Menggunakan Enam Metode Forecasting. Forum Ilmiah, 10(2), 198-208.

Sugiyono. (2011). Metode Penelitian Kuantitatif, Kualitatif dan $R \&$ D. Alfabeta.

Wardah, S., \& Iskandar, I. (2017). Analisis Peramalan penjualan Produk Keripik Pisang Kemasan Bungkus (Studi Kasus: Home Industry Arwana Food 
Tembilahan). J@ Ti UNDIP: Jurnal Teknik Industri, 11(3), 135-142. https://doi.org/10.14710/jati.11.3.135-142

Yanti, N., Tuningrat, I. A. M., \& Wiranatha, A. (2016). Analisis peramalan penjualan produk kecap pada perusahaan kecap Manalagi Denpasar Bali. Jurnal Rekayasa dan Manajemen Agroindustry, 4, 72-81. 